\title{
Correspondence
}

\section{Collect reliable data on embryo selection}

The rise in prenatal screening and preimplantation genetic diagnosis over the past 30 or so years has been accompanied by deselection of fetuses and embryos. To our knowledge, governments or international bodies do not systematically collect societywide reliable data on the grounds for and numbers of selective abortions and deselected embryos. As society enters an era in which less-invasive prenatal testing and discussions about possible human reproductive genome editing promise to accelerate prenatal selection, the need for good data is compelling.

Many people are concerned about the social effects these technologies might have. What if more countries move towards the elimination of Down's syndrome, as in Iceland? Is there a difference, in principle, between therapy and enhancement? Ten years from now, will trait selection be a fact of society? Without good data, people have two poor choices: to ignore possible societal effects, or to interfere in the doctor-patient relationships in which these technologies are deployed. We suggest a third way.

We call for the systematic collection of anonymized data on how many embryos and fetuses are deselected per institution per year, and for which conditions. Reported to a government agency or international body, the information would provide a baseline against which jurisdiction-specific trends in selection could be assessed.

People who have disabilities, together with other key stakeholders, laypeople and experts, would then be in a position to assess the social impact of human selecting technologies and to make recommendations for action to mitigate negative effects as appropriate.

Charis Thompson ${ }^{\star}$ Science FARE, University of California, Berkeley, USA. charis@berkeley.edu

${ }^{*}$ On behalf of 6 correspondents (see go.nature.com $/ 2 y 8 d z a b$ for full list).

\section{Circadian biology for public health}

The award of the 2017 Nobel Prize in Physiology or Medicine has piqued public and scientific interest in circadian research (see Nature 550, 18; 2017). The time has come to translate our understanding of the circadian molecular clock into publichealth benefits.

Circadian biology is the archetypal gene-environment interaction. We know that certain transcription factors interact with each other in a loop to produce the biological outputs that make up 24-hour patterns. And we know that light and time-zone travel affect the timing of this system to the detriment of human health. But even after 30 years of circadian biology, we still don't know how best to use this information to protect the public's health.

Some activities that disrupt circadian clocks are voluntary. Others can be the result of limited opportunity — as in the case of night-shift workers. Scientists and the public need to engage in dialogue to develop precautionary and mitigation strategies that are feasible and acceptable to all.

Charleen Adams University of Bristol, UK.

Erika Blacker, Wylie Burke University of Washington, Seattle, USA.

charleen.adams@bristol.ac.uk

\section{Sherlock Holmes - a family likeness?}

We might be able to learn more about Sherlock Holmes's physical appearance, beyond Sidney Paget's 1893 illustration of the fictional sleuth at work (see M. Konnikova Nature 549, 332-333; 2017).

In Arthur Conan Doyle's

'Adventure of the Greek

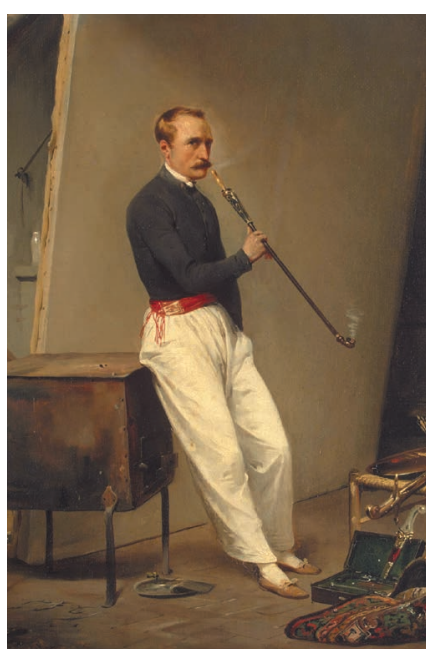

Interpreter', Holmes mentions that his grandmother was " $\mathrm{a}$ sister of Vernet, the French artist". Émile Jean-Horace Vernet (1789-1863) and his grandfather Claude-Joseph Vernet

(1714-1789) were both painters. There are several self-portraits by Émile Jean-Horace Vernet (see, for example, go.nature. com/2gohp80), and there is a striking portrait of ClaudeJoseph Vernet by ElisabethLouise Vigée Le Brun (1788) at the Louvre Museum in Paris (see go.nature.com/2hlacgw).

These paintings show that Sherlock Holmes's purported great-uncle and his great-greatgrandfather share an aquiline nose and piercingly intelligent eyes - two of the characteristics featured in Paget's illustration. And one of the self-portraits by Émile Jean-Horace Vernet shows the painter smoking a pipe (pictured).

Eric L. Altschuler Metropolitan Hospital, New York, USA. altschue@nychhc.org

\section{Sustainability crisis brews in EU forestry}

The European Parliament decided in September that member states of the European Union can increase forest harvesting, provided the forest's carbon sink remains positive and sustainable forest-management practices are not violated. This decision did not include a proviso for reducing carbon emissions in other sectors to compensate for the net increase of emissions that will result from the increased harvesting. This requirement was specified by the European Commission and the European Parliament's Committee on Environment, Public Health and Food Safety (ENVI), and is in accord with the Paris agreement.

Forestry is not sustainable unless it conserves the biodiversity of forest ecosystems and maintains forest resources and their contribution to global carbon cycles, while also fulfilling four other criteria (see go.nature.com/2gkkqrw). Allowing increased harvests is likely to violate two of the sustainability criteria by causing carbon emissions to rise for decades compared with the status quo (see go.nature. com/2yucysr) and by failing to maintain forest biodiversity (see go.nature.com/2zeo2sd).

To avert a sustainability crisis, Europe must impose a strict upper limit on forest harvesting and formulate policies to stimulate carbon sequestration. The limit should be set to enhance forest carbon reservoirs and promote long-lasting wood products to replace goods responsible for high emissions, such as concrete and steel.

Janne S. Kotiaho University of Jyväskylä, Finland. Markku Ollikainen University of Helsinki, Finland. Jyri Seppälä Finnish Environment Institute, Helsinki, Finland. janne.kotiaho@jyu.fi

\section{CONTRIBUTIONS}

Correspondence may be sent to correspondence@ nature.com after consulting the author guidelines at http://go.nature.com/ cmchno. Alternatively, readers may comment online: www.nature.com/ nature. 